\title{
Development of Submerged Biofilter Design for Wastewater Conservation: Carbonaceous Removal Study
}

\author{
A W Satria ${ }^{1}$, H Wijayanti ${ }^{2}$, W Febrianti ${ }^{3}$, M H A Nur ${ }^{4}$, and A Prasetya ${ }^{5}$ \\ ${ }^{1}$ Chemical Engineering Department, Institut Teknologi Sumatera, Lampung Selatan, Lampung \\ ${ }^{2}$ Biology Department, Institut Teknologi Sumatera, Lampung Selatan, Lampung \\ ${ }^{3}$ Mathematics Department, Institut Teknologi Sumatera, Lampung Selatan, Lampung \\ ${ }^{4}$ Architecture Department, Institut Teknologi Sumatera, Lampung Selatan, Lampung \\ ${ }^{5}$ Chemical Engineering Department, Universitas Gadjah Mada, Yogyakarta
}

\begin{abstract}
This stuy aims to determine the operational parameters of submerged biofilter and to develop a model that can be used to estimate the elimination rate of pollutant using aerob and anaerob reactors. The experiment was conducted with draining the wastewater on a cylindrical biofilter column. The removals of wastewater were processed with hidraulic loading rate (HLR) variation of $0.44 ; 0.74 ; 1.11 ; 1.66 ; 2.21 \mathrm{~m}^{3} / \mathrm{m}^{2} /$ day. Samplings were performed at the various height of column, i.e. $0.15 ; 0.3 ; 0.45 ; 0.6 ; 0.75$ and $0.9 \mathrm{~m}$. Then the effluent from each point was analyzed using UV-Vis Spectrophotometer. The results showed that the optimum carbonaceous removal was obtained at column height of $90 \mathrm{~cm}$. The operational parameters for scale-up application is $0.74 \mathrm{~m}^{3} / \mathrm{m}^{2} /$ hour. While the removal percentage of carbon as a chemical oxigen demand (COD) parameter is $84.72 \%$. The changes of HLR will give an effect on the substrate reduction rate (SRR), the microorganism's growth rate, and the percentage of substrate removal. The model was developed based on efficiency factors can represent the concentration of COD effluent at the various of HLR and the height of column.
\end{abstract}

\section{Introduction}

Liquid waste or wastewater is the waste which the existences give problem in people's lives. The high mobility characteristic make this waste contaminate the environment easily. According to Indonesian Government Regulation Number 82 of 2001 about Water Quality Management and Water Pollution Control $^{[1]}$, identifies that it is not allowed to dispose of liquid waste into water or soil, except with the permission from the regent and based on the assessment results.

Liquid waste from industry contains chemical compounds, heavy metals, hazardous and toxic materials, and various organic compounds in high concentrations. For liquid waste from the resident (domestic) the largest component is solids, either in soluble or suspended. These solids contain organic substances, such as carbohydrates, proteins, fats and oils, and inorganic substances, e.g. calcium, chloride, iron and others $^{[2]}$.

Organic waste are usually contains of carbon, hydrogen, oxygen, nitrogen, phosphorus, sulphur and other minerals which enter the water in form of precipitated solids, colloids, suspended or dissolved. Carbon, nitrogen and phosphorus are three types of concern contaminants because at certain levels would lead to adverse effects for some organisms ${ }^{[2,3]}$.

One of the biological wastewater treatment techniques is submerged biofilter. Submerged biofilter is wastewater treatment plant using microorganisms which growed in a packing media (attached culture) and the processed fluid is passed continuously across the media ${ }^{[4,5]}$. In this study will try to process the wastewater containing high concentration of carbonaceous pollutans with submerged biofilter.

\section{Liquid Waste}

The contributor contaminants can pose the aquatic environment are dirty water, excess nutrients, synthetic organic compounds, litter, plastics, metals, hydrocarbons/oils, and polycyclic aromatic hydrocarbons. Nitrogen (nutrient) and carbonaceous are important to maintain aquatic ecosystems, but 
if excess the concentration will damage the aquatic environment. According Dombrowski ${ }^{[6]}$ the average concentration of COD in the domestic wastewater ranged from 444.5 to $775.9 \mathrm{mg} / 1$.

2.1 Biological Wastewater Treatment

Biological waste treatment reactor can be divided into two parts ${ }^{[7]}$, e.g.:

2.1.1 Suspended growth reactor.

In this reactor, microorganism grows in a suspended culture. Activated sludge process is a reactor of this type.

2.1.2 Attached growth reactor (attached growth reactor).

In this reactor, the microorganisms grow on media support to form a thin layer (film) to $\operatorname{attach}^{[8]}$. This type of reactor are trickling filters, biological discs, submerged filters, and fluidized reactor.

\subsection{Submerged Biofilter}

Submerged biofilter is a submerged attached growth bioreactor (SAGB) that uses granular packing, which the liquid waste passed across the media continuously and always under submerged conditions. The presences of the media causes microorganisms grow, attached and form a thin layer (biofilm) on the surface ${ }^{[4,5,7]}$.

This treatment process can be done with aerobic biofilter, anaerobic or combined anaerobic-aerobic processes $^{[9]}$. The process of aerobic-anaerobic combination are used to eliminate (removed) nitrogen content. For the removal of nitrogen, under aerobic conditions occur nitrification process, i.e. ammonium is converted to nitrate $\left(\mathrm{NH}_{4}{ }^{+} \rightarrow \mathrm{NO}_{3}{ }^{-}\right)$and the anaerobic conditions occur denitrification process, i.e. nitrate formed is converted into nitrogen $\left(\mathrm{NO}_{3}{ }^{-} \rightarrow \mathrm{N}_{2}\right)^{[10,11]}$.

\subsection{Modeling Transport in Submerged Biofilter}

The mass transfer approach model which occurs in the biofilter is following the model developed by Grady et al ${ }^{[7]}$, i.e. the substrate flux into and out of biofilm surface should be proportional to the overall rate of substrate utilization in cross-sectional area of the biofilter. The difference of substrate consumption rate every point with the overall consumption on the surface of biofilm, must be an effectiveness factor which gave the average correction factor that describes the mass transfer equation can represent the overall mass transfer in the biofilm surface ${ }^{[12]}$.

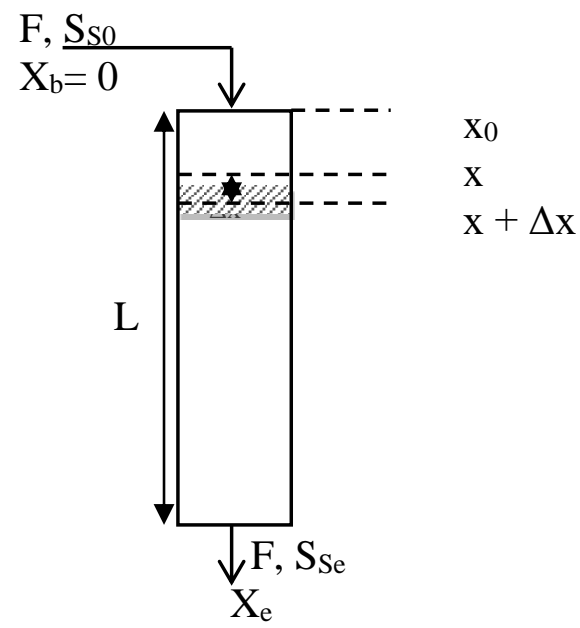

Figure 1. Flow of the substrate in the biofilter

Substrate mass balance equations in the Figure. 1 are:

$\{R$. of input $\}-\{R$. of output $\}-\{R$. of degradation by attached and suspended biomass $\}=\{R$.

of accumulation\} 
$F .\left.S_{S a}\right|_{x}-\left.F \cdot S_{S a}\right|_{x+\Delta x}-\eta_{e}\left(\frac{q_{H} S_{S a}}{K_{S}+S_{S a}}\right) \cdot X_{b} \cdot$ as. Ac. $\Delta x \cdot L_{f}$

$$
\begin{array}{r}
-\left(\frac{q_{H} \cdot S_{S a}}{K_{S}+S_{S a}}\right) \cdot f_{a c} \cdot \Delta x \cdot A c \cdot Y_{x / s}\left(S_{S 0}-S_{S a}\right)=0 \\
\frac{\mathrm{d} S_{S a}}{\mathrm{dx}}=-\eta_{e}\left(\frac{q_{H} \cdot S_{S a}}{K_{S}+S_{S a}}\right)\left(\frac{a s \cdot A c}{F}\right) X_{b} \cdot L_{f}-\left(\frac{q_{H} \cdot S_{S a}}{K_{S}+S_{S a}}\right)\left(\frac{f_{a c} \cdot A c}{F}\right) Y_{x / s}\left(S_{S 0}-S_{S a}\right)
\end{array}
$$

at: $\mathrm{x}=0, \mathrm{~S}_{\mathrm{Sa}}=\mathrm{S}_{\mathrm{S} 0} ;$ and $\mathrm{x}=\mathrm{L}, \mathrm{S}_{\mathrm{Sa}}=\mathrm{S}_{\mathrm{Se}}$

From differential equation (eq. 2) is obtained the relationship between the concentrations of waste out of the biofilter ( $\mathrm{Sse}$ ) to the length/height of media (L) (eq 3). The values of qH and Ks are calculated by regression of the data which obtained in the experiment.

$$
\mathrm{S}_{\mathrm{Se}}=\frac{\left(\mathrm{Y} \cdot \mathrm{S}_{\mathrm{S}_{0}}+\mathrm{X}\right) \mathrm{q}_{\mathrm{H}} \cdot \mathrm{S}_{\mathrm{So}}}{\mathrm{Y} \cdot \mathrm{q}_{\mathrm{H}} \cdot \mathrm{S}_{\mathrm{SO}}\left(1-\exp \frac{\mathrm{L}}{\left(\frac{\mathrm{K}_{\mathrm{S}}}{\left(\mathrm{Y} \cdot \mathrm{S}_{\mathrm{SO}}+\mathrm{X}\right) \mathrm{q}_{\mathrm{H}}}+\frac{1}{\mathrm{Y} \cdot \mathrm{q}_{\mathrm{H}}}\right)}\right)+\left(\mathrm{Y} \cdot \mathrm{S}_{\mathrm{SO}}+\mathrm{X}\right) \mathrm{q}_{\mathrm{H}} \exp \frac{\mathrm{L}}{\left(\frac{\mathrm{K}_{\mathrm{S}}}{\left(\mathrm{Y} \cdot \mathrm{S}_{\mathrm{SO}}+\mathrm{X}\right) \mathrm{q}_{\mathrm{H}}}+\frac{1}{\mathrm{Y} \cdot \mathrm{q}_{\mathrm{H}}}\right)}}
$$

which:

$$
\begin{aligned}
& X=\left(\frac{a s \cdot A c}{F}\right) \eta_{e} \cdot X_{b} \cdot L_{f} \\
& Y=\left(\frac{f_{a c} \cdot A c}{F}\right) Y_{x / s} \\
& F=H L R \cdot A_{c}
\end{aligned}
$$

\section{Methods}

To reduce levels of carbonaceous pollutants (as Cemical Oxygen Demand) through the process in the aerobic reactor are varied the hydraulic load rate (HLR) on the packing length of the reactor i.e. 15, 30, $45,60,75$ and $90 \mathrm{~cm}$. The initially concentration of waste is around $500 \mathrm{ppm}$ and the hydraulic retention times are $30,18,12,8$, and 4 hours (HLR variation: $0.44 ; 0.66 ; 1.11 ; 1.74 ;$ and $2.21 \mathrm{~m}^{3} / \mathrm{m}^{2} /$ day).

\section{Results and Discussion}

Decreasing concentration profile of wastewater on a varieties of column length and HLR expressed in Figure 2. From the this graph shows that the process of elimination wastes is success only for first and second HLR. This success is based on environmental quality standards for wastewater according Indonesian Ministry of Environment Regulation No. 5 of 2010 e.g., 80 mg/l 


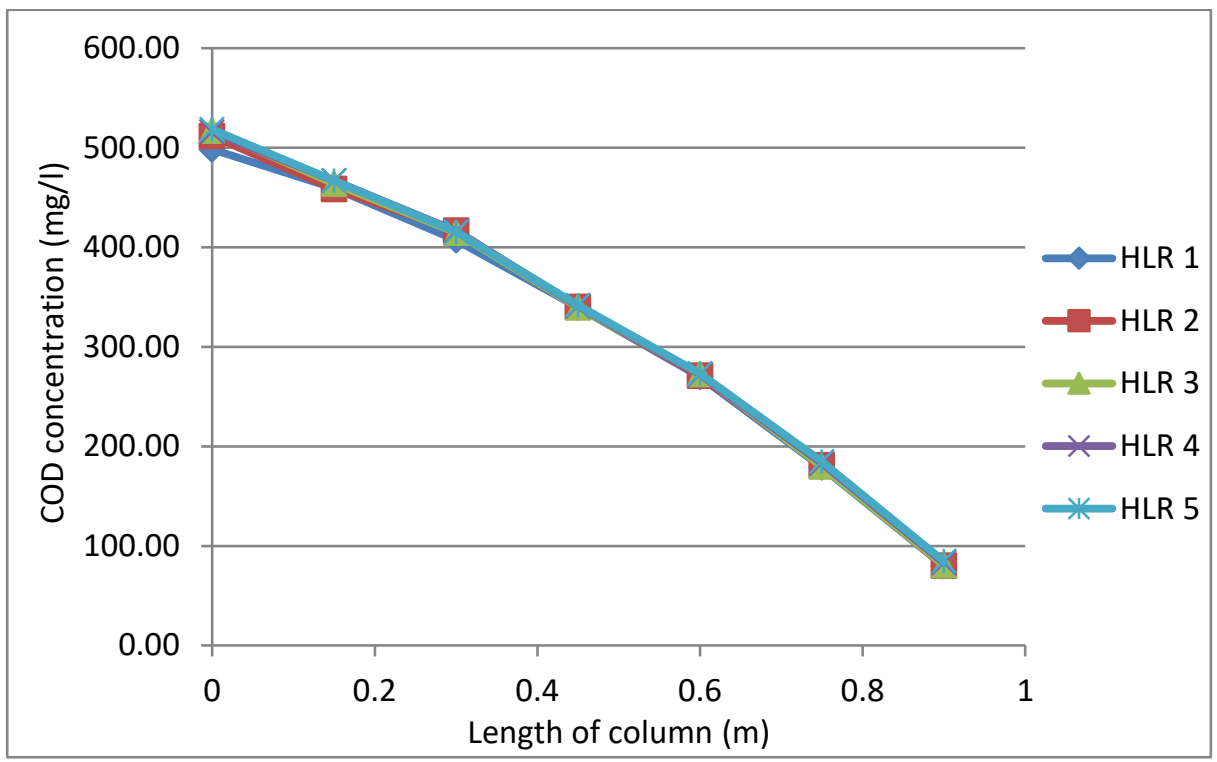

Figure 2. The relations between the average effluent concentrations and column lengths for each HLR

Meanwhile, the relations between the HLR with SRR (substrate reduction rate) at various length of the column is presented in Figure 3. From the graph shows that the substrate reduction rate by microorganisms is affected by the hydraulic loading rate of wastewater into the biofilter. The larger value of HLR, will affect the greater substrate reduction rate of ammonia and nitrate. For this waste, the maximum value of HLR and length of reactor $\left(2.21 \mathrm{~m}^{3} / \mathrm{m}^{2} / \mathrm{d}\right.$ and $\left.90 \mathrm{~cm}\right)$, the profile consistent linearly.

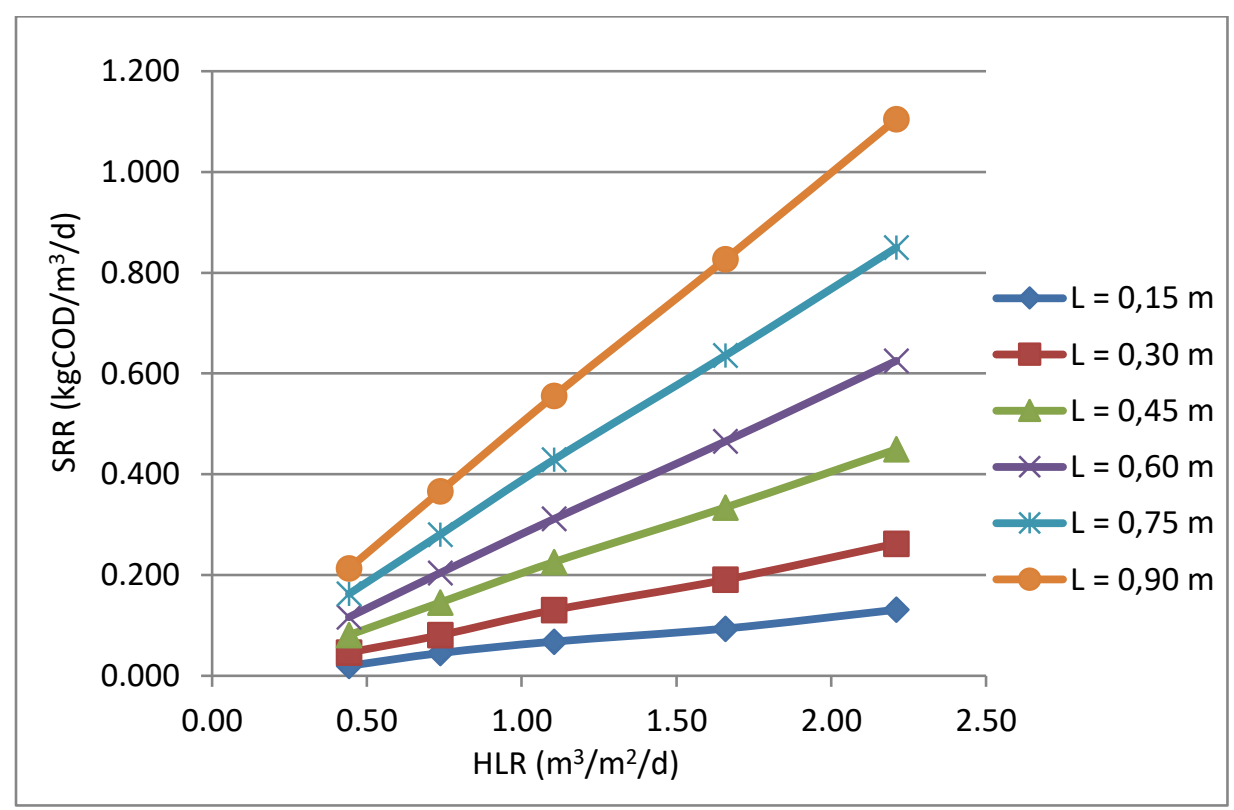

Figure 3. The relations between SRR to HLR at various length of column reactors. 
The relationship between the HLR with a percentage of substrate removal at various length of the column is presented in Figure 4. From the graph, it show that a good design for a removal effluent are the reactor length of $75 \mathrm{~cm}$ and $90 \mathrm{~cm}$. Tests on variations HLR up to $2.21 \mathrm{~m}^{3} / \mathrm{m}^{2} / \mathrm{d}$, it can remove pollutants above $80 \%$. But if prefer to the environmental quality standards for the disposal only the biofilter with a length of column $90 \mathrm{~cm}$ and HLR 0.44 to $0.74 \mathrm{~m}^{3} / \mathrm{m}^{2} / \mathrm{d}$ that can meet the criteria.

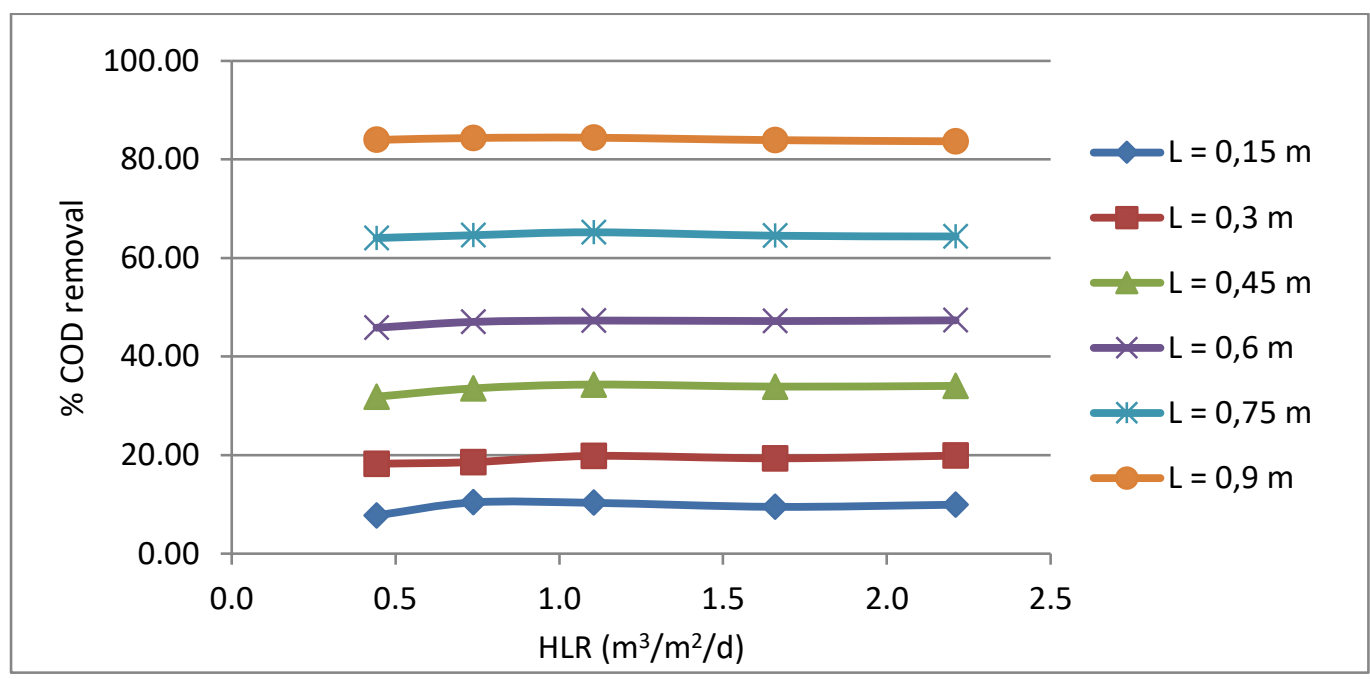

Figure 4. The relations between the averages of percentages removal with HLR at various length of column reactors.

Meanwhile, the model result is used to predict the magnitude of reduction concentrations can be seen in Figure 5. From the graph can be seen that the model for decreasing COD concentration is well verified to describe the percentage substrate removal, it was seen that the highest percentage reduction occurred at the HLR $0.74 \mathrm{~m}^{3} / \mathrm{m}^{2} /$ day. The reduction in percentage for the waste is $84.72 \%$ and the model gives a value of $84.36 \%$.

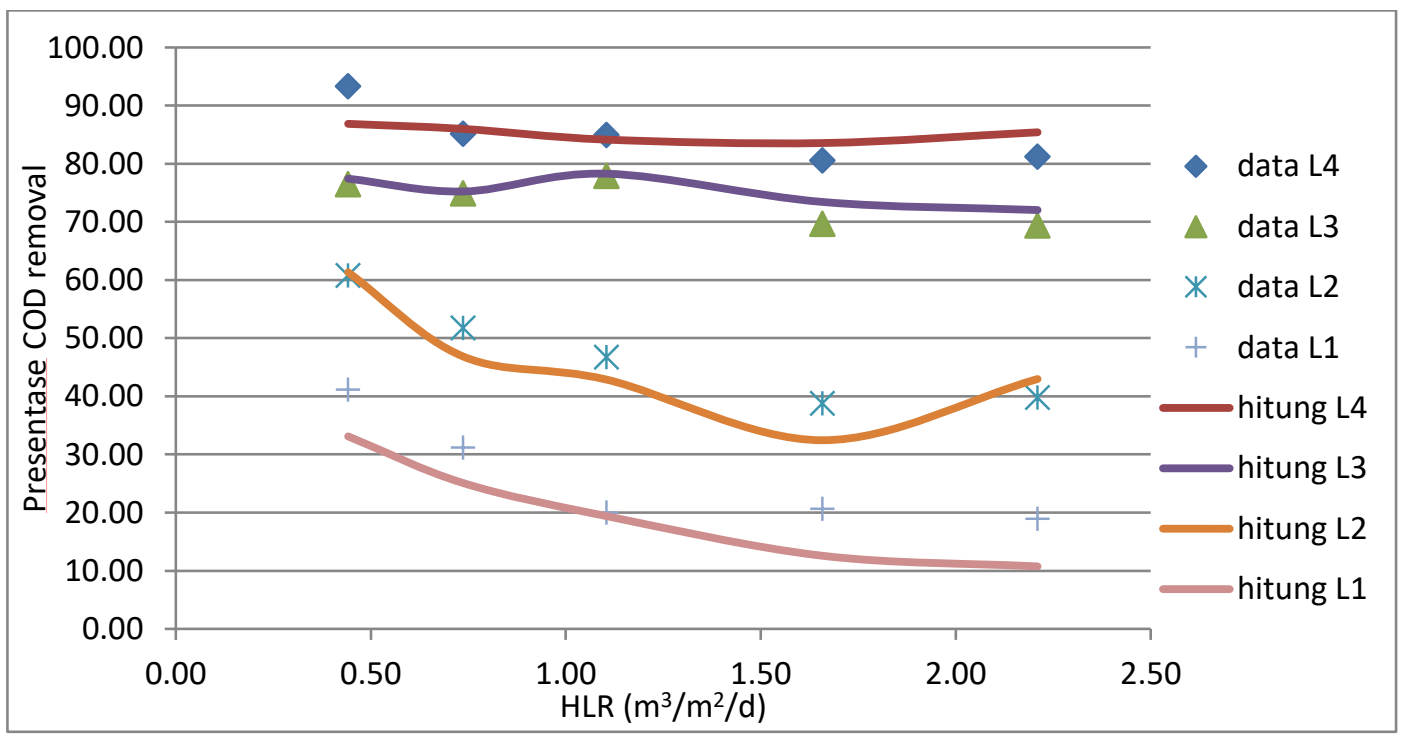

Figure 5. The relations between precentage removal models and experiments on the HLR 


\section{Consclusions}

Based on the research results obtained some conclusions, e.g.:

1. Wastewater containing carbonaceous pollutan (as COD) can be processed using submerged biofilter at the best design at column reactor of $90 \mathrm{~cm}$.

2. The optimal hydraulic loading rate to eliminate COD accordance the environment standard is $0.74 \mathrm{~m}^{3} / \mathrm{m}^{2} /$ day and the removal percentage is $84.72 \%$.

3. The mass transfer model was developed based on the efficiency factor can verify to represented the amount of effluent substrate concentration at various HLR and the length of reactor.

6. References

[1] Peraturan Menteri Lingkungan Hidup Indonesia Nomor 5 Tahun 2010 tentang Baku Mutu Air Limbah.

[2] Davis M L and Cornwell D A 1991 Introduction to Environmental Engineering $2^{\text {nd }}$ edition, (New York: McGraw-Hill)

[3] Rittman B E and Mc Carty P L 2001 Environmental Biotechnology: Principles and Application, (New York: McGraw Hill International Ed)

[4] Metcalf and Eddy 2003 Waste Water Engineering: Treatment, Disposal and Reuse $4^{\text {th }}$ ed. (New York: McGraw Hill Book Co.) p 307

[5] Chaudhary D S, Vigneswaran S, Ngo H H, Shim W G, and Moon H 2003 Biofilter in water and wastewater treatment Korean J. Chem. Eng. 6 1054-65

[6] Dombrowski E M, Wiesmann U and Choi I S 2007 Fundamental of Biological Wastewater Treatment (Weinheim: Wiley-VCH Verlag GmbH \& Co. KGaA) p 223-62

[7] Grady J C P, Daigger G T and Lim H C 1999 Biological Wastewater Treatment Second Edition. (New York: Marcell Dekker Inc) p 949-83

[8] Bryers J D 2000 Biofilms II Process Analysis and Application (New York: Jhon Wiley and Sons Inc) p 159-206

[9] Kumar K V, Sridevi V, Harsha N, Lakshmi M V V C and Rani K 2013 Biofiltration and its application in treatment of air and water pollutants-a review Int. J.of Appl. or Innov. in Eng. \& Mgmt 9

[10] Clabaugh M M 2001 Nitrification of Landfill Leachate by Biofilm Columns Thesis Env. Eng. (Virginia Polytechnic Institute and State University)

[11] Wang Q and Chen Q 2016 Simultaneous denitrification and denitrifying phosphorus removal in a full-scale anoxic-oxic process without internal recycle treating low strength wastewater J.of Env. Sci 39 175-83

[12] Wang R et al 2009 Nitritation performance and biofilm development of co- and counter- diffusion biofilm reactors: modeling and experimental comparison. J. of the Int. Wtr. Ass. 43 2699-709

\section{Acknowledgments}

This research was supported by the Hibah Mandiri ITERA Smart, Program for Superior Research Category. We would grateful to Dr. Agus Prasetyo as supervior for assistance in many ascpects. 